\title{
Development of False Ceiling Board Using Indigenous Sheep Wool Fiber Reinforcement/Gypsum Matrix Composite
}

\author{
Etsehiwot Yisma W/Amanuel ${ }^{1}$, Fekade Dejene Mengesha ${ }^{2}$ and Awoke Fenta Wodag ${ }^{1 *}$ \\ ${ }^{1}$ Ethiopian institute of Textile and Fashion Technology Bahir, Dar University, Ethiopia \\ ${ }^{2}$ Wolkite University, department of Textile engineering, Ethiopia
}

*Corresponding author: Awoke Fenta Wodag, Ethiopian institute of Textile and Fashion Technology Bahir, Dar University, Ethiopia.

Received Date: January 25, 2021

Published Date: April 07, 2021

\begin{abstract}
A false ceiling is a ceiling made beneath the main ceiling of the room, building and other related applications. In this research Composite ceiling board based on short wool fibers and gypsum was developed by hand lay-up process. A three-factor two-level experimental design central composite design method was applied to develop the composites and explore the contribution of each parameter on mechanical properties. The present investigation focuses on the physical and mechanical characterization of the sheep wool fiber-reinforced polymer-matrix composites and

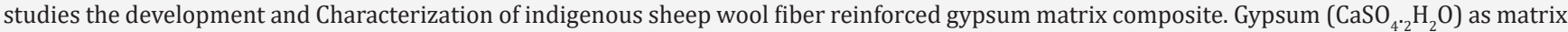
and wool as reinforcement would be used as light-weight material for false ceiling board. Experimental investigation has been carried out to find out the effect of wool fiber at different weight percentages starting from 10 to $35 \% .100 \mathrm{KN}$ servo hydraulic universal testing machine was used to test specimen. The optimum proportion of the raw materials were identified using central composite design and the results are, $30 \%$ fiber, $70 \%$ gypsum and parallel fiber arrangement, Regarding to the optimum value, mechanical properties such as tensile strength, compressive strength and cross arrangement for bending strength of the composite material were characterized. The result showed that the maximum tensile strength was $7.6 \mathrm{~N} /$ $\mathrm{mm} 2$, compressive strength was $6.6 \mathrm{~N} / \mathrm{mm}^{2}$ and bending strength is $5.4 \mathrm{~N} / \mathrm{mm}^{2}$. As a result, indigenous sheep wool fiber as reinforcement of false ceiling board has better mechanical properties than other wood, wood with fiber-based composite.
\end{abstract}

Keywords: Indigenous sheep; Wool fiber; Gypsum; Fiber orientation; False ceiling board; Fiber-gypsum ratio

\section{Introduction}

Ethiopia is the first in livestock population in Africa and tenth in the world , Large population livestock sector plays a significant role contributing $15-17 \%$ of the total GDP and $35-49 \%$ of agricultural GDP in the country providing export commodities like live animals, hides, and skins to earn foreign Exchanges [1]. Ethiopia has possessed 30,612,976 sheep population of hybrid and exotic sheep broad categories. Among the population, Menz sheep could be adapted to the rugged climate of the region and can thrive on poor quality roughage [2,3].
However, sheep wool fiber has not been fully utilized for composite applications. The researchers reported about 90 million sheep in the EU and producing 270.000- tons of wool. An estimated 10\% is low-grade coarse wool and needs to be disposed [4]. Its length usually ranges from 1.5 to 15 inches ( $38 \mathrm{~mm}$ to $380 \mathrm{~mm}$ ) depending on the breed of sheep. Natural organic fibers have a very important role in the alleviation of the housing problem. They not only occur in luxurious abundance in many parts of the world, but can also lead directly to energy savings, conservation of the world's most scarce resources and protect human and environment [5]. But in 
Ethiopia, the application of sheep wool is not well-known, and the government does not give enough support on the integration of both textile and agricultural sectors.

Natural fiber-based composites have good performance under various experimental settings and material conditions. Although natural fibers possess the potential to enhance the properties of the composites, investigations show several drawbacks. There are fibers incompatibility with hydrophobic polymers, fibers aggregations during processing, poor moisture resistance, inferior fire resistance, low strength, short durability, and limited processing temperature. Because of those reasons the application of natural fibers in composites is still limited. Growth of composite usage also came about fast because of increased awareness regarding product performance and increased competition in the market for a lightweight and also easy availability of components. Composite materials have the potential to replace widely used steel and aluminum, and many times with better performance [6].

Fiber -reinforced polymer matrix got considerable attention in numerous applications because of the good properties and superior advantages of natural fiber over synthetic fibers in term of its relatively low weight, low cost, less damage to processing equipment, good relative mechanical properties such as tensile modulus and flexural modulus, improved surface finish of molded parts composite, renewable resources, being abundant, flexibility during processing, biodegradability, and minimal health hazards [7]. The sheep wool fiber reinforcement in a composite material was applied in different protective and decorative applications. In general, we can use wool fiber in different application areas like textile manufacturing, and as reinforcement with others matrix material, with low initial investments like false ceiling board.

A false ceiling is a ceiling made beneath the main ceiling of the room, building and other related applications. Gypsum boards and Plaster of Paris (POP) are two of the most commonly used materials for creating a false ceiling [8].

Approximately $80 \%$ of the global sheep wool production is intended to be used in the textile industry, from the total amount. However, existing sheep wool fiber in Ethiopia and neighboring countries is not suitable for application in the textile industry. Properties of the wool depend on its chemical composition and complex protein structure. In its natural state, raw wool from sheep contains several constituents other than the $[4,9]$. In modern technology, Composite materials are the most important, adaptable material and sophisticated engineering material introduced in the world. Composite materials strength-to-weight ratio proportions compared to standard materials and design flexibility of these components fulfills the requirements on the applicable area. Wool is the natural fiber obtained from sheep, cashmere, rat, and goats. It is extracted by the skin of Sheep it is an eco-friendly, low cost and possesses good characteristics [3].
Therefore, this research work tries to substitute the use of wood and plastic based on the product with lightweight and better performance on both physical and mechanical properties such as moisture absorption, tensile, bending, compressive, and other parameters by using indigenous sheep wool fiber as reinforcement with gypsum matrix by designing of false ceiling board by using indigenous sheep wool fiber reinforcement on integrating with an eco-friend binder gypsum and it is important to increase the alternative use of indigenous wool fiber as a composite rather than textile application.

\section{Literature of Review}

\section{Natural fiber composite}

Natural fiber reinforcement composites are important to the industry because of their low density and ecological advantages over conventional use of composites. Industrial application composites are gaining importance due to their compatibility and bio-degradable nature. Because of that Natural fiber reinforcement composites are very cost-effective material for different application areas from storage devices to building construction [10].

For use of animal-based natural fibers like silk and wool in a composite material has been rarely reported. Concentration towards biodegradable material is increasing day to day due to severe concerns on managing impacts of carbon emissions in a sustainable manner and the environmental requirements on safe and effective disposal of plastic polymer material after [11].

\section{Matrix}

A Matrix is part of the composite material in which it surrounds the fibers and thus protects those fibers against chemical and environmental attacks. For fibers to carry a maximum load, the matrix must have a lower modulus and greater elongation than the reinforcement [12]. Polymer matrix composites are used in modernday structural applications due to their significant advantages such as opposition to corrosion, resistance to chemicals, high strength to weight ratio, poor thermal and electrical conductivity, and low moisture absorption. Adhesion has been defined as "the procedure of joining two dissimilar materials through an adhesive agent that solidifies during the bonding process". Four different mechanisms of adhesion have been identified, including mechanical adhesion, adsorption, diffusion, and electrostatic cohesion. Mechanical adhesion relies on interlocking (keying) of the adhesive into the irregularities of bonding surfaces to promote adhesion [13].

\section{Materials and Methods}

\section{Materials}

The wool fiber is collected from Menz, Amhara region, Ethiopia. The indigenous sheep wool fibers were used as reinforcement material in this composite. Different amounts of sheep wool and gypsum material are collected from the market based on 
availability. Manual molding system, glass mirror (for molding the board) in Figures 1 \&2 below, and metal plate are used to form the ceiling and the testing machine used to measure the strength of the product. The wool fiber is collected from Menz, Amhara, Ethiopia.

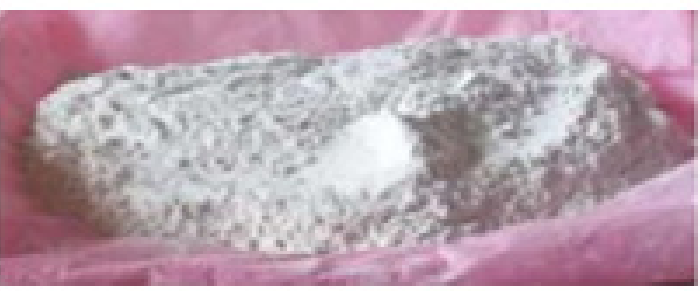

Figure 1: Gypsum powder.

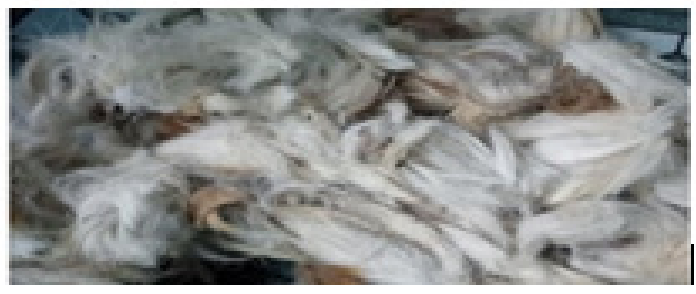

Figure 2: Short length wool fiber

\section{Physical Property of wool Fiber}

Density of fiber is $1.31 \mathrm{~g} / \mathrm{cm} 3$, Length: 35 to $124 \mathrm{~mm}$, the color of wool fiber could be white, near white, brown and black. Flame reaction Odor of burnt horn, luster of coarse fiber is higher than fine fiber. Moisture Regain is $11.5-14 \%$, very absorbent, decrease strength when wet, seem warmth, will shrink in washing. Electrostatic reaction highly electrostatic at dry conditions, Strength Tenacity dry $=1.32 \mathrm{~g} / \mathrm{d}$, Wet $=$ dry 0.69 weak (due to few H-bond) Elasticity Breaking extension - $39.5 \%$, Recovery \% - 65 at $5 \%$, Elongation at break standard elongation is $21-28 \%$ and $25-44 \%$ in wet condition. Feel or Hand Soft. Resiliency Excellent (due to crimp) Abrasion resistance Good, Dimensional stability Bad (For tendency of felting), Heat affects the wool fiber greatly, Effect of Sun Light, the fibers become discolored and develop a harsh feel.

\section{Gypsum}

Using Abay Gypsum as matrix. It is purchased from the local shops in Addis Ababa, Ethiopia. It is one of the most exciting polymer types and is used in advance to produce composite material with different reinforcing elements. Its extensive use is mainly for its suitable mechanical properties and adhesion, good possibility of utilizing addition- type reaction as well as for low cure shrinkage and low cost. After the preparation of composite board different response of test results were prepare and finally, the optimum value of composite ratio depending up on the results. The expected response of the experiment is depending up on the requirements of false ceiling board. So, the board must be fulfilling the standards. The present studies on natural fiber, like indigenous sheep wool fiber reinforced to gypsum matrix to create new composite materials, mechanical and physical properties are evaluated, and their properties are compared to glass fiber reinforced epoxy composite.

\section{Methods}

\section{Preparation of the composite}

Indigenous sheep wool fiber was collected from the place more it will be available and to characterize the physical properties then, to prepare parallel arrangement of the fiber for measurement of fiber orientation. Secondly, prepare the wool fiber cross arrangement for good compression with the parallel arrangement of composite products. Preparation of the composites consisted of layer formation the gypsum and sheep wool fibers, with the corresponding percentage.

\section{Molding method}

Making composite production of natural fibers does not complex on molding comparing to make composite to thermoplastic fibers. Because thermoplastic fibers need a high amount of temperature and pressure for melting as well as make bonding for the formation of the composite. But wool fiber reinforcement composite production easily molded in manually by layer to layer formation with gypsum material within room temperature.

\section{Design and development of composite}

Hand lay-up technique is used for a composite development method. It is the simplest method of composite processing. Composite materials can be prepared by different methods. However, due to many reasons such as particle size and shape, cost, 
familiarity with the technique and availability of tools, composite is design and develop using hand lay-up techniques. During the design and development of composite, the mold with dimension of $300 \times 200 \times 20 \mathrm{~mm}\left(\mathrm{~L}^{*} \mathrm{~W}^{*} \mathrm{~T}\right)$ were used. The fiber length is kept between $20-40 \mathrm{~mm}$. The proportion of the fibers is varying from 10 to $35 \%$ on the dry weight of gypsum.

\section{Molding Designs}

The mix design optimization was developed with dispersion method. Gypsum were weighted in dry state and then water is poured and to stir thoroughly to make stable dispersion. Then the mixture is poured into the molds then, to laying the fiber on the gypsum with a consecutive process until to fulfill the required parameters of the false ceiling board.

\section{Model design for making false ceiling board using sheep wool fiber and gypsum composite}

The model design used for talking the ratio of the composite material are central composite design, on this model the numeric and categorical factors are available. Both have its own levels depending upon the factors used to optimize the material.

\section{Composite fabrication process}

The wool fiber and matrix volume weight should be determined, then formation of gypsum slurry, and put the gypsum slurry on the mold and then to laying the wool fiber. The composite was cured at room temperature until it was dry. Finally, wool fiber reinforced gypsum composite ceiling board is fabricated as follow (Figure 3):

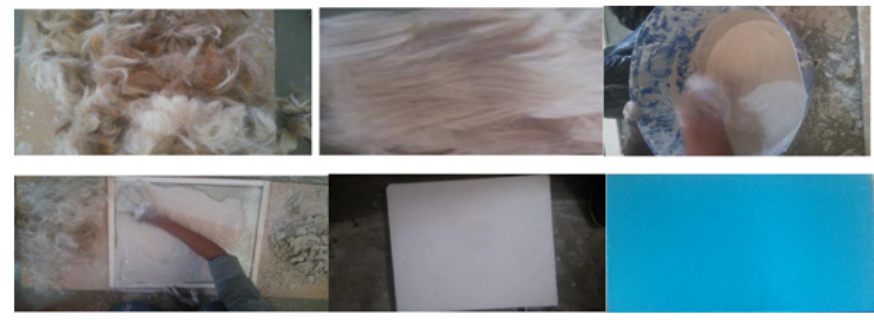

Figure 3: Steps to develop the composite products.

\section{Physical parameters}

Tensile strength measurement: The tensile test is done by cutting the composite specimen as per ASTM: D1037 standard, sample dimension is $(150 * 50 * 10) \mathrm{mm}$. A universal testing machine (UTM) (Model: WAW-100 is used for testing with a maximum load rating of $100 \mathrm{KN}$. The load is applied until the specimen breaks and tensile strength is recording [14-16].

\section{Bending testing}

The bending test is done by cutting the composite specimen as per ASTM: D790 standard (sample dimension is $(150 * 50 * 10)$ $\mathrm{mm}$ at WPTC Testing Laboratory. This test is carrying out in the universal testing machine. A universal testing machine (UTM) (Model: WAW-100 is used for testing with a maximum load rating of $100 \mathrm{KN}$. When a load is applied in the middle of the specimen, it bends and fractures.

\section{Compressive strength testing}

This test is a contrasting force that pushes inward upon the specimen from opposite sides. It determines the behavior of a material while it experiences a compressive load by measuring variables. It is done using universal tensile testing machine as per ASTM D1037 standard, sample dimension is $25 * 25 * 10 \mathrm{~mm}$.

\section{Water absorption test measurement}

The water absorption test of sheep wool fiber reinforced gypsum composite is tested through immersion in distilled water at room temperature. The sample was taken out periodically and after wiping out the water from the surface of the sample, then to weight immediately using a precise electronic balance machine to find out the content of water absorbed. The specimens are weighting regularly at $2,4,6$, and 24 hours and then water absorption is calculated by the weight difference.

\section{Experiments Set Up}

\section{Experimental methods}

Three specimens are taken in order to show the repeatability of the results to minimize the experimental errors for each test, after the composite boards are prepared. And then test pieces are cut properly. Finally, experimental investigation is done through prepared test pieces on universal testing machine by varying the sample that made from different ratio of wool fiber and gypsum components.

The tensile test was conducted along the longitudinal direction of the (sheep wool fiber reinforcement gypsum composite) SWFRGC on universal testing machine according to ASTM. The bending test was also conducted at the middle span of the specimen of the SWFRGC on universal testing machine according to ASTM [17].

\section{Experimental Conditions}

Testing Conditions: The experiment was conducted at constantstrain-rate-values in quasi-static condition for tensile, compressive and bending testing under constant room temperature. Tensile test 
of the fabricated composite was conducted using electrohydraulic UTM at WPTC Mechanical technology Testing Laboratory condition (room temperature \& humidity) at across head speed of $0.75 \mathrm{~mm}$ / min. Similarly, the bending test was also conducted on electro.

\section{Experimental setup}

Universal Testing Machine (UTM) for tensile and bending and compressive test: All the mechanical tests were investigated using Computer Controlled Electro- Hydraulic Servo Universal Testing Machine model: WAW-100; which has a capacity of up to $100 \mathrm{kN}$, with $0.01-500 \mathrm{~mm} / \mathrm{min}$ test speed. This universal testing machine could be test three types of mechanical properties of material are tensile strength, compressive strength and bending strength. By changing the setting and jaws of the machine in the screen of the machine then test all properties.

\section{Result and Discussion}

The product developed with a mold size of $300 \mathrm{~mm} * 200 \mathrm{~mm}$ and followed steps of prepare the raw materials/fiber and gypsum, the fiber laying into layer by layer, pressing $(20 \mathrm{~kg} / \mathrm{m} 2$ and 10 minutes), finally curing $\left(5\right.$ minutes at $85^{\circ} \mathrm{C}$ ) was performed. The proportion of the factors became up to optimum the product was not good, such as surface roughness and strength problem. The combination of indigenous wool fiber and gypsum material we can produce a false ceiling board that are used for decorative and aesthetic purpose on the interior part of the house. These developments are used to substitute the heavy weight material and environmental noncompatible material with a low cost as well as easy accessibility material. The produced samples were prepared as per ASTM: D1037 standards, three different composite specimen samples were tested, and the average results were taken in each test [18].

Hydraulic universal testing machine using a cross head speed of about $1.5 \mathrm{~mm} / \mathrm{min}$. During the test, load is continuously applied to all the specimens from dynamometer load cell until the specimen fails.

\section{Analysis of Tensile Strength}

The tensile test is done by cutting the composite specimen as per ASTM: D1037 standard (sample dimension is $(150 * 50 * 10) \mathrm{mm}$. A universal testing machine (UTM) (Model: WAW-100 is used for testing with a maximum load rating of $100 \mathrm{KN}$. The load is applied until the specimen breaks and tensile strength is recording (Figures $4 \& 5)$.

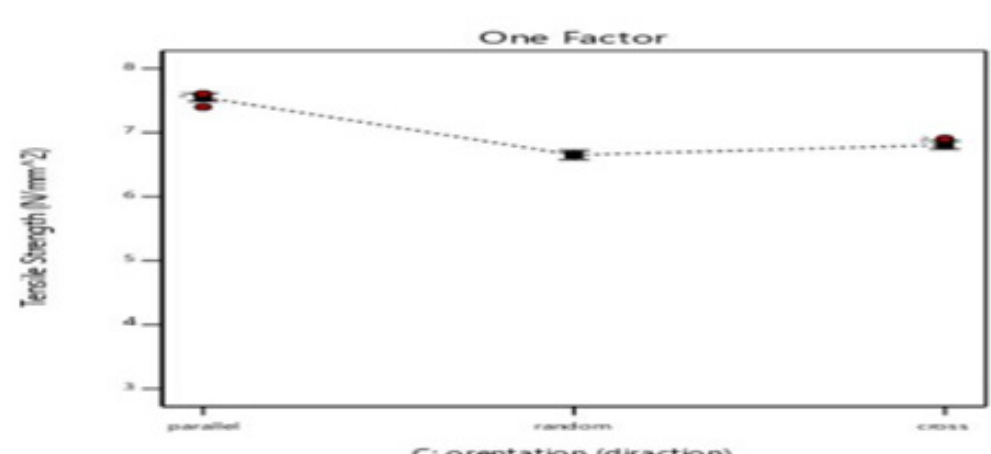

Figure 4: Effect of wool fiber orientation on the tensile strength of composite material.

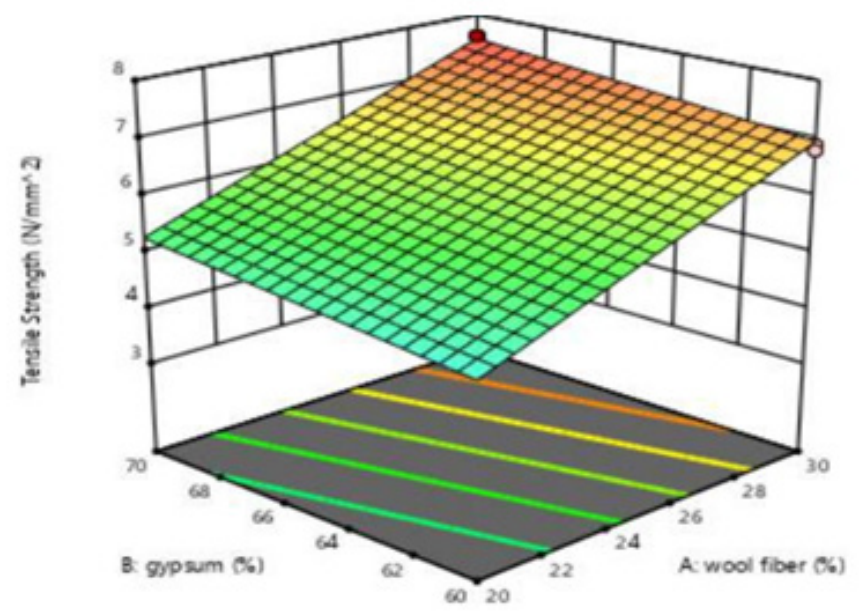

Figure 5: Effect of wool fiber orientation on the tensile strength of composite material. 
3D surface used to identify the optimum position of the factors over the response surface. In figure 5 the 3D shows the wool fiber, gypsum increase, and a parallel arrangement of fiber, the tensile strength is increased up to an optimum point on the longitudinal direction. As shown in figures 4 to 5 above, tensile strength, in $30 \mathrm{wt} \%$ of wool fiber composition on parallel arrangement of fiber is higher than the others 10 to $35 \mathrm{wt} \%$ on 38 different samples of indigenous sheep wool fiber compositions. From those 38-samples test run to consider that when the fiber weight increases, it also increases tensile strength however, after $30 \%$ wt fiber composition, the test results show tensile strength are decreased. This decreased in tensile strength is may be due to the maximum void contents and weak interfacial adhesion in case of composites and manufacturing method (hand lay-up), And by itself, it is not suitable to fabricate i.e. when the material is stressed in tension test, it tends to elongate. When the bond between wool fibers and gypsum weakens, it leads to the loosening of wool fibers and to fracture of the material. Finally, the result obtained was compared with glass fiber reinforced epoxy standard specimen that does not have any additives. The wool fiber reinforced gypsum composite cannot be compared with glass fiber reinforced epoxy composite because glass fiber reinforced epoxy composite has very higher tensile properties [19].

\section{Bending testing}

The bending test is done by cutting the composite specimen as per ASTM: D790 standard (sample dimension is $(150 * 50 * 10)$ $\mathrm{mm}$ at WPTC Testing Laboratory. This test is carrying out in the universal testing machine. The figure below illustrates the effect of fiber orientation on the bending strength of composite material (Figure 6).

A universal testing machine (UTM) (Model: WAW-100 is used for testing with a maximum load rating of $100 \mathrm{KN}$. When a load is applied in the middle of the specimen, it bends and fractures. As illustrated in figure 6, the arrangement of fiber with the interaction of the factors such as wool fiber, gypsum has a significant effect on the bending strength of the composite material up to optimum point.

Compressive strength test: A compressive test is an opposing force that pushes inward upon the specimen from opposite sides. It determines the behavior of a material while it experiences a compressive load by measuring variables. Compressive strength test done using universal tensile testing machine as per ASTM D1037 standard (sample dimension is $25 * 25 * 10 \mathrm{~mm}$ ). It is more discussed based on the figure below.

This 3D view in Figure 7 aids us to identify the focal position of the factors over the response surface and the best compressive strength. It shows the increment of wool fiber and gypsum at parallel arrangement of fiber the compressive strength also increases up to optimum point. The compressive strength graphs are shown on the above figures. There is a significant difference between the compressive strength value between different proportions of fibers as well as between fibers. Compressive strength is the capacity of a material or structure to withstand axially directed pushing force. It provides data of force verses deformation for the test method.

Generally, as shown in figure 7 compressive strength, in 30wt\% of wool fiber composition on parallel arrangement of fiber is higher than the others 10 to $35 \mathrm{wt} \%$ ranges on 38 different samples of indigenous sheep wool fiber gypsum compositions. From this different sample test run to consider that when the fiber weight increases, it also increases compressive strength however, after $30 \%$ wt fiber composition, the test results are decreased. This decreased in compressive strength is may be due to the maximum void contents and weak interfacial adhesion in case of composites and manufacturing method (hand lay-up), And by itself, it is not suitable to fabricate i.e. when the material is compressed in tension test, it tends to break and when the material compressed. And when the bond between wool fibers and gypsum weakens, it leads to the loosening of wool fibers and to fracture of the material [20].

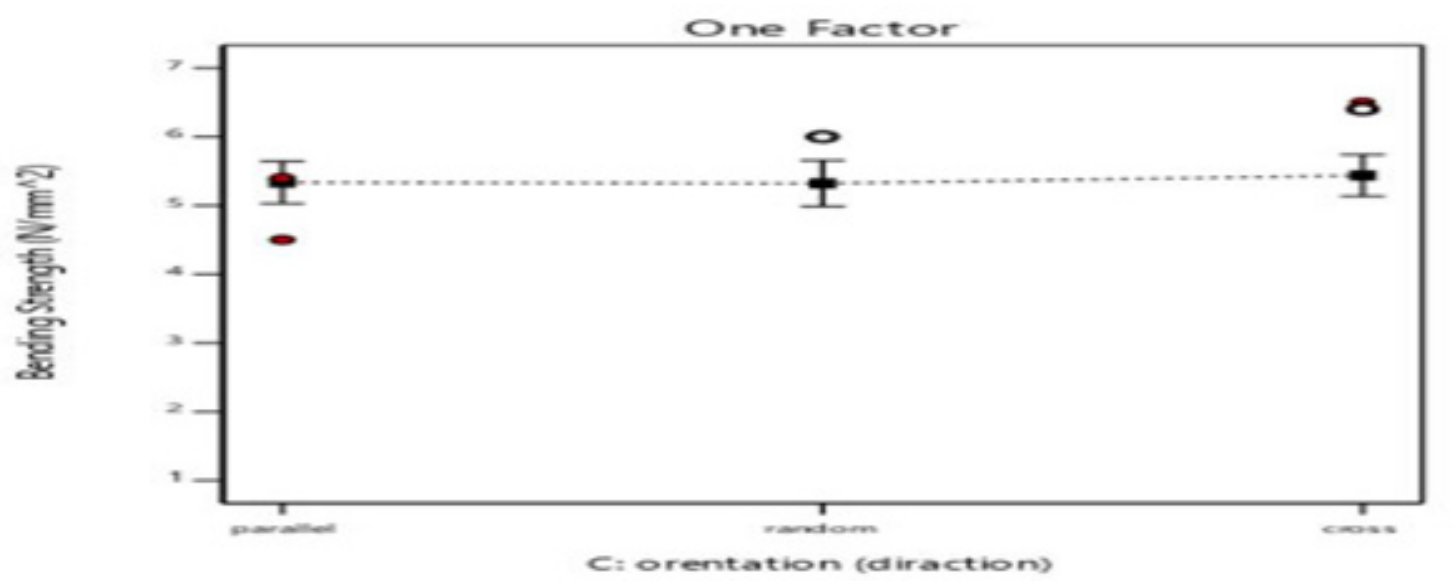

Figure 6: Effect of fiber orientation on the bending strength of composite material. 


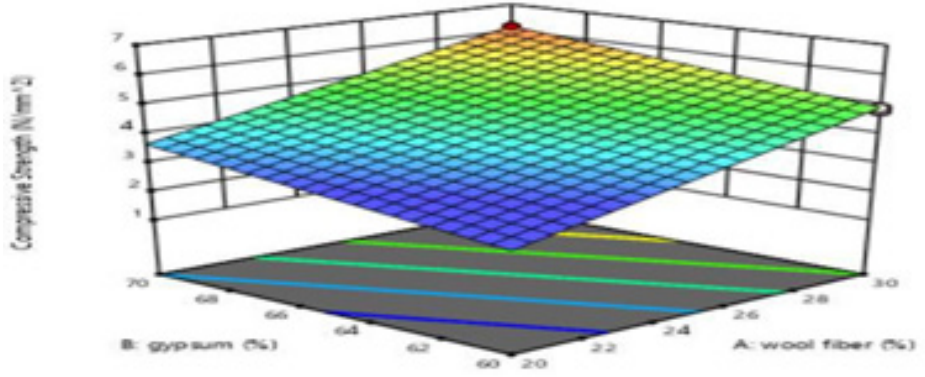

Figure 7: 3D view optimum position factors over compressive strength of composite material.
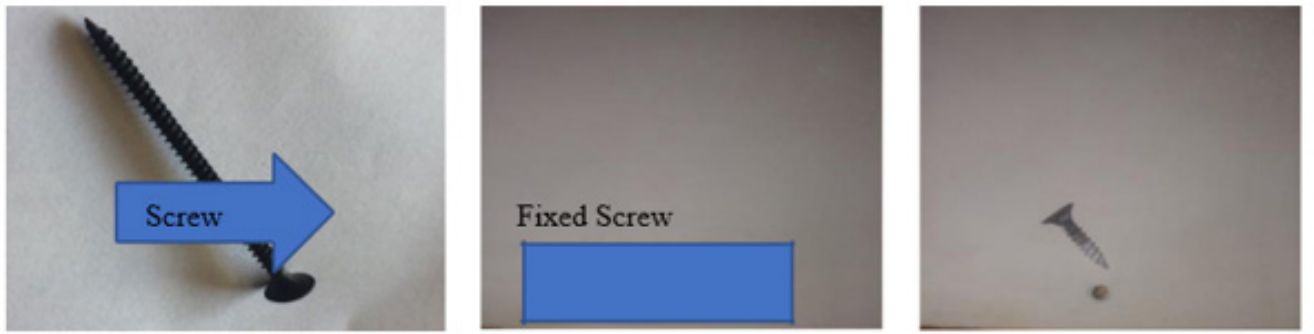

Figure 8: Screwing effect for composite board.

\section{Water absorption test measurement}

The water absorption parameter of sheep wool fiber reinforced gypsum composite is tested complete immersion in distilled water at room temperature. The sample was taken out periodically and after wiping out the water from the surface of the sample, then to weight immediately using a precise electronic balance machine to find out the content of water absorbed. The specimens are weighting regularly at $2,4,6$, and 24 hours. The water absorption is calculated by the weight difference.

The different amount of fibers when studied on the research work, it was found that there is a significant effect on the moisture content of composite, as the fiber percentage increased the moisture content increased gradually. Fibers used in this study are hygroscopic in nature they tend to absorb moisture quickly and the pores in composites tend to absorb moisture. From the investigation, it is observed results that moisture has not increased more than $3 \%$ which can be considered as under controlled one [21].

As expected, there was an increase in the rate of water absorption when the residue quantity of the composite was increased. When samples (composites) stayed in water more hours, water absorption also increases up to optimal point, at the intervals of every $2 \mathrm{hrs}$, $4 \mathrm{hrs}, 6 \mathrm{hrs}$, and $24 \mathrm{hrs}$. The higher the adhesion (bond) between the matrix and the fiber, the fewer will be the sites that could store water, leading to lower water absorption. a special treatment with alkalis like sodium hydroxide is at times given to the fiber, it could minimize water absorption of specimens. However, it is not necessary that much reducing the absorption of water in this research because the fabricated materials of false ceiling are for the purpose of internal parts of the house as a construction material. And painting outer part of the materials is necessary for both as a decoration of house and reducing water absorption.

\section{Screwing effect}

Electric Screwdriver was used to drive a $3 \mathrm{~mm}$ screw into the board. This was repeated for ten more boards. After three blows the boards showed no sign of cracks visible to naked eyes and screw half driven in. The screw was fully pushed in and also no cracks visible to naked eyes and the screw were held firmly in the board. Although no latest testing machine is used during this test investigation, the boards could be screwed successfully based on naked eye observation (Figure 8).

\section{Conclusion}

Wool fibers reinforced with gypsum composite was manufactured from different weight ratio starts 10 up to $35 \%$ of wool fiber and 65 up to $90 \%$ gypsum for the total of 39 sample model, where it was determined experimentally. The produced composite ceiling boards were successfully screwed with firm grips. This composite material compares favorably with other commercially available ceiling board materials. This study has equally shown that waste materials can be used into other useful materials application, such as indigenous sheep wool fiber ceiling boards. A polymer matrix composite contains the indigenous sheep wool fiber as reinforcement was successfully fabricated 
and the tensile, flexural, and compressive test results where it is found that $30 / 70 \mathrm{wt} . \%$ has better mechanical property among the other fiber-matrix composition. The manufactured product carried out mechanical properties testes is, tensile strength $(7.6 \mathrm{~N} / \mathrm{mm} 2)$ as per ASTM D1039, bending strength $(5.4 \mathrm{~N} / \mathrm{mm} 2)$ as per ASTM D3410 and compressive strength $(6.6 \mathrm{~N} / \mathrm{mm} 2)$ as per ASTM D1037.

The parallel arrangement of fibers on these composites has good tensile and compressive strength because the force is applied in the longitudinal direction of the fiber arrangement and it leads to the high resistance of the material. But on bending strength the cross arrangement has good. These happen the applied force acts on the perpendicular point of the intersection and the force is distributed all over the cross-sectional area of the material's has high resistance of the applied load.

\section{Acknowledgement}

The Author would like to thank Ethiopian institute of Textile and Fashion Technology Bahir, Dar University, Ethiopia for the financial funding and providing access necessary materials for the successful completion of the research.

\section{Conflict of Interest}

The author declares that they have no conflict interest.

\section{References}

1. Getu A (2015) Review on Challenges and Opportunities Sheep Production: Ethiopia. African Journal of Basic \& Applied Sciences 7: 200205.

2. Sitotaw D, Woldemariam A, Tesema A (2019) Characterizing the Wool Fiber Fineness and Crimps of Menz,Dorper and Their Crossbreed Sheep. J Inst Eng India Ser E 100: 121-129.

3. Shalwan A, Yousif BF ((2013) In State of Art: Mechanical and tribological behaviour of polymeric composites based on natural fibres. Materials \&Design 48: 14-24.

4. Štirmer N, Milovanovic B, Sokol JM (2014) Cement Composites Reinforced with Sheep's Wool.

5. Oladele IO, Akinwekomi AD, Aladenika AK (2009) Development of Fibre Reinforced Cementitious Composite for Ceiling Application. Journal of Minerals \& Materials Characterization \& Engineering 8: 583-590.

6. Sisay E (2011) Design and Analysis of Thick Partition Wall for Building from Local Composite "Enset" Fiber. Addis Ababa University, Ethiopia.

7. Mohammed L, Ansari MMN, Jawaid M (2015) A Review on Natural Fiber Reinforced Polymer Composite and Its Applications. International Journal of Polymer Science 2015: 1-15.
8. Dawood ET, Mezal AM (2014) The Properties of Fiber Reinforced Gypsum Plaster. Journal of Scientific Research \& Reports 3: 1339-1347.

9. Štirmer N, Bojan M, Mislav SJ (2014) Cement composites reinforced with sheep's wool. Proceedings of the International Symposium on Eco-Crete 1: $271-278$

10. Bongarde US, Shinde VD (2014) Review on natural fiber reinforcement polymer composites. International Journal of Engineering Science and Innovative Technology 3: 431-436.

11. Abilash N, Sivapragash M (2013) Environmental benefits of ecofriendly natural fiber reinforced polymeric composite materials. International Journal of Application or Innovation in Engineering \& Management (IJAIEM) 2: 2319-4847.

12. Azam S, Mohsen H, Zeini M (2016) Investigations on the Reinforcement of Mechanical Properties of Gypsum Composites Containing E-glass Woven Fabrics. Journal of textiles and polymers 4(1): 20-26.

13. Shalwan A, Yousif BF (2012) Mechanical and tribological behaviour of polymeric composites based on natural fibres.

14. Biswas S, Deo B, Patnaik A, Satapathy A (2011) Effect of fiber loading and orientation on mechanical and erosion wear behavior of glass epoxy composites. Polymer Composite 32(4): 665-674.

15. Prashanth B, Shivananda HK, Niranjan HB (2012) Influence of Fiber Orientation and Thickness on Tensile Properties of Laminated Polymer Composites. International Journal of Pure and Applied Sciences and Technology 9(1): 61-68.

16. Kim NK, Bhattacharyya D, Lin R (2013) Multi-functional Properties of Wool Fibre Composites. Advanced Materials Research 747: 8-11.

17. Garoushi SK, Lassila LV, Tezvergil A, Vallittu PK (2006) Fiber-Reinforced Composite Substructure: Load-Bearing Capacity of an Onlay Restoration and Flexural Properties of the Material. J Contemp Dent Pract 7(4): 1-8.

18. Mazumdar SK (2002) Composites Manufacturing Materials Product and Process. CRC press, USA.

19. Jorge Perdigão SE (2006) Fundamental Concepts of Enamel and Dentin Adhesion. In: Sturdevant's Art and Science of Operative Dentistry. Mosby Elsevier.

20. Ataguba (2016) Properties of ceiling boards produced from a composite of wastepaper and rice husk clement oguche department of civil engineering. International federal polytechnic, 1037, idah, Nigeria.

21. Rafael Rodolfo de Melo (2014) Production of agro -waste composite ceiling board, A Case Study of the Mechanical Properties Physical and Mechanical Properties of Particleboard Manufactured from Wood, Bamboo and Rice Husk Instituto de Ciências Agrárias e Ambientais, Universidade Federal de Mato Grosso - UFMT, CEP 78557-267, Sinop, MT, Brazil. 